\title{
O DIREITO À SAÚDE E A DISPENSAÇÃO JU- DICIAL DE MEDICAMENTOS NO BRASIL: A FERRAMENTA E-NATJUS
}

\author{
THE RIGHT TO HEALTH AND JUDICIAL DISPOSAL OF \\ MEDICINAL PRODUCTS IN BRAZIL: THE E-NATJUS TOOL
}

\author{
João Paulo K. Forster ${ }^{1}$ Najwa Dagash ${ }^{2}$ \\ Paula Franciele da Silva ${ }^{3}$
}

DOI: https://doi.org/10.37767/2591-3476(2020)04

RESUMEN:

El artículo examina el derecho a la salud de la dispensación judicial de medicamentos en Brasil y la posibilidad de utilizar la herramienta e-Natjus como elemento de apoyo técnico para los jueces en estas decisiones. El propósito de este breve estudio es, basado en el derecho a la salud, definir cuáles son los criterios adoptados en el poder judicial para el suministro de medicamentos en Brasil, examinados a partir de la necesidad de una protección efectiva a los tribunales. El estudio del tema está justificado, ya que los Poderes Legislativo y Ejecutivo no han podido desarrollar e implementar políticas públicas a la misma velocidad que los ciudadanos los necesitan. Así, el poder judicial, no diseñado tradicionalmente para el desarrollo de políticas públicas, en la práctica lo ha estado haciendo, con consecuencias de todo tipo. Con este fin, se realizó una investigación exploratoria en doctrina, legislación y jurisprudencia, utilizando el método deductivo.

\section{RESUMO:}

O artigo examina o direito à saúde a partir da dispensação judicial de medicamentos no Brasil e a possibilidade do uso da ferramenta e-Natjus como elemento de suporte técnico aos magistrados nessas decisões. O objetivo deste breve estudo é, a partir do direito à saúde, definir quais são os critérios adotados no Judiciário para o fornecimento de medicamentos no Brasil, examinados a partir da necessidade de tutela efetiva aos jurisdicionados. Justifica-se o estudo do tema, uma vez que os Poderes Legislativo e Executivo não têm conseguido desenvolver e implementar políticas públicas na mesma velocidade que os cidadãos delas necessitam. Assim, o Poder Judiciário, não tradicionalmente projetado para o desenvolvimento de políticas públicas, na prática o vem fazendo, com consequências de toda sorte. Para tanto, realizou-se pesquisa de cunho exploratório, em doutrina, legislação e jurisprudência, valendo-se do método dedutivo.

\footnotetext{
1 Mestre e Doutor em Direito pela UFRGS. Professor da Graduação e do Programa em Pós-Graduação Stricto Sensu (Mestrado) em Direitos Humanos do Centro Universitário Ritter dos Reis - Laureate International Universities - UniRitter. Advogado. E-mail: joao_forster@uniritter.edu.br. ORCID iD: http:// orcid.org/0000-0002-4229-9309.

2 Mestranda em Direitos Humanos - bolsista CAPES, Especialista em Direito Público com ênfase em Direito Administrativo e Graduada em Direito pelo Centro Universitário Ritter dos Reis - Laureate International Universities - UniRitter. E-mail: najwadagash@hotmail.com. ORCID iD: http://orcid.org/00000001-9148-1687.

3 Mestranda em Direitos Humanos pelo Centro Universitário Ritter dos Reis - Laureate International Universities - UniRitter. Graduada em Direito pela CNEC Gravataí. Advogada. E-mail: paulatoldo@gmail.com. ORCID iD: http://orcid.org/0000-0003-2247-7574.
} 


\begin{abstract}
The article examines the right to health from the judicial dispensation of medication in Brazil and the possibility of using the e-NatJus tool as technical support for judges in these decisions. The purpose of this brief study is, based on the right to health, to define what are the criteria adopted in the Judiciary for supplying medication in Brazil, based on the need for effective protection by the jurisdiction. The study of the subject is justified, since the Legislative and Executive Powers have not been able to develop and implement public policies at the same rate as citizens need them. Thus, the Judiciary, not traditionally designed for the development of public policies, in practice has been doing so, with all sorts of consequences. To this end, an exploratory research was conducted in doctrine, legislation and jurisprudence, applying the deductive method.
\end{abstract}

PALABRAS CLAVE: Derecho a la salud; Judicialización; Medicinas;

Políticas públicas; e-Natjus.

PALAVRAS-CHAVE: Direito à Saúde; Judicialização; Medicamentos;

Políticas Públicas; e-Natjus.

KEY WORDS: Right to Health; Judicialization; Medicine; Public

Policies; e-NatJus

\title{
I. Considerações Iniciais
}

O reconhecimento do direito à saúde, consectário do direito à vida, com todas as suas garantias, tem por objetivo assegurar, dentre outros pilares, a dignidade da pessoa humana. Preservar o direito à saúde significa, portanto, atribuir dever fundamental ao Estado de que assegure uma ampla gama de condições e serviços para que os cidadãos possuam efetivamente tal direito, especialmente a partir do estabelecimento de políticas públicas. Verifica-se, no entanto, que os Poderes Legislativo e Executivo não têm conseguido desenvolver e implementar políticas públicas na mesma velocidade que os cidadãos delas necessitam. Isto ocorre especialmente em áreas de acelerado desenvolvimento tecnológico, como no caso de tratamentos medicinais. Os procedimentos burocráticos para inclusão de medicamentos em listas oficiais podem se revelar excessivamente lentos diante da necessidade efetiva dos cidadãos de tratamento urgente.

Por esse e tantos outros fatores, se apresenta, desde muito, intensa judicialização das questões envolvendo saúde no Brasil. O Poder Judiciário, não tradicionalmente projetado para o desenvolvimento de políticas públicas, na prática o vem fazendo, com consequências de toda sorte. O objetivo deste breve estudo é, a partir da compreensão do direito à saúde, definir quais são os critérios adotados no Judiciário para o fornecimento de medicamentos no Brasil, examinados a partir da necessidade de tutela efetiva aos jurisdicionados.

Percebe-se que o Brasil, assim como tantos outros ordenamentos jurídicos, optou por um magistrado com formação exclusivamente jurídica. Essa constatação exige que, em demandas envolvendo situações complexas como a indicação do tratamento mais adequado, particularmente naquelas em que se requer o fornecimento de fármacos, o juiz 
deve se valer de conhecimento técnico especializado para fundamentar adequadamente sua decisão. Nesse contexto, a ferramenta e-Natjus desenvolvida pelo Conselho Nacional de Justiça (CNJ) se insere como instrumento de grande valia para a prolação de decisões tecnicamente embasadas, escoradas em evidências científicas e não em uma visão estritamente jurídica do tema. Para tanto, realizou-se pesquisa de cunho exploratório, em doutrina, legislação e jurisprudência, valendo-se do método dedutivo.

\section{Direito à Saúde no Brasil}

Inicialmente, cumpre ressaltar a existência de um amplo rol de direitos e garantias fundamentais assegurados aos seres humanos nos três níveis territoriais, ou seja, a pessoa (cidadão) tem seus direitos humanos e fundamentais garantidos e efetivados, pelo menos teoricamente, tanto regionalmente quanto nacionalmente, e, ainda, em âmbito internacional.

Há diversos direitos essenciais aos seres humanos, como por exemplo, o direito à liberdade, à igualdade ${ }^{4}$; contudo, mesmo que teoricamente, não exista hierarquia entre os direitos fundamentais. Observa-se que, de forma orgânica, o direito à vida tem maior relevância entre os demais, uma vez que, só é possível efetivar os demais direitos quando se tem vida (aqui, fala-se em vida em sentido primário, o de estar vivo).

Uma vez que se vive e se tem o direito à vida garantido, extrai-se desse direito primordial um direito secundário, o direito à saúde. É no direito à saúde que se tem a manutenção da vida e por consequência, sua real efetividade. Por isso, implicitamente, pode-se entender e ponderar que o direito à vida seria um dos principais direitos dos seres humanos e que nele encontra-se o amplo direito à saúde, objeto desse estudo, dada a importância de buscar uma garantia efetiva a este direito para que seja possível usufruir e efetivar demais garantias fundamentais a plena existência.

Nas palavras de Martini e Sturza, confirma-se que a saúde é um direito humano fundamental que resguarda todo e qualquer sujeito (caráter universal) e, ainda, apresenta-se o direito à saúde como um dos elementos da cidadania, uma vez que o direito à saúde é direito à vida.

“[...] encontra-se a saúde como um direito humano que todo o sujeito tem e pode exercer, sendo considerada, inclusive, como um dos importantes elementos da cidadania, como um direito à promoção da vida das pessoas, pois direito à saúde é direito à vida. A questão do direito à saúde é universal e consolida-se como um direito humano fundamental." ${ }^{\prime 5}$

Adota-se, como ponto de partida, a criação da Constituição da Organização Mundial da Saúde (OMS), em 22 de julho de 1946 (pós $2^{\text {a }}$ Guerra Mundial), ratificada por 51 membros da ONU e de outros 10 Estados. Ela estabelece dez princípios ${ }^{6}$ basilares à felicidade dos

\footnotetext{
4 Art. $5^{\circ}$ Todos são iguais perante a lei, sem distinção de qualquer natureza, garantindo-se aos brasileiros e aos estrangeiros residentes no País a inviolabilidade do direito à vida, à liberdade, à igualdade, à segurança e à propriedade [...].

5 MARTINI, Sandra Regina; STURZA, Janaína Machado (2019): Direitos Humanos: saúde e fraternidade, Evangraf, Porto Alegre, p. 36.

6 1. A saúde é um estado de completo bem-estar físico, mental e social, e não consiste apenas na ausência de doença ou de enfermidade; 2 . Gozar do melhor estado de saúde que é possível atingir constitui um dos direitos fundamentais de todo o ser humano, sem distinção de raça, de religião, de credo político, de condição econômica ou social; 3. A saúde de todos os povos é essencial para conseguir a paz e a segurança e depende da mais estreita cooperação dos indivíduos e dos Estados; 4. Os resultados conseguidos por cada Estado na promoção e proteção da saúde são de valor para todos; 5 . O
} 
povos, às suas relações harmoniosas e à sua segurança. O primeiro princípio elencado conceitua e esclarece a abrangência do direito à saúde: "a saúde é um estado de completo bem-estar físico, mental e social, e não consiste apenas na ausência de doença ou de enfermidade."

Em seguida, a Declaração Universal dos Direitos Humanos de 1948 surge como forma de institucionalização universal dos direitos humanos, elencando taxativamente quais são os direitos humanos inatos aos indivíduos. ${ }^{8}$ Com intuito de complementar e alargar a Declaração Universal dos Direitos Humanos e de ressaltar a obrigatoriedade de cumprimento de tais direitos, no ano de 1966 são edificados dois pactos - o Pacto Internacional sobre Direitos Civis e Políticos e o Pacto Internacional sobre Direitos Econômicos, Sociais e Culturais. Porém, o "Pacto Civil" só entrou em vigor em 1976, tendo seus preceitos juridicamente vinculantes. No artigo 12-1 do referido Pacto, os EstadosPartes reconhecem o direito de toda pessoa de desfrutar o mais elevado nível de saúde física e mental.

Tem-se que a Declaração de Alma-Ata sobre Cuidados de Saúde Primária de 1978 é um dos documentos de maior relevância internacional ao tema do direito à saúde. Ela amplia a definição dada pela OMS e o reafirma como um direito humano fundamental, acrescentando "que a consecução do mais alto nível de saúde possível é o objetivo social mundial mais importante, cuja realização requer a ação de muitos outros setores sociais e econômicos, além do setor da saúde." ${ }^{\prime 9}$

Em âmbito nacional, a positivação do direito à saúde foi dada pela Constituição Federal de 1988, no capítulo dos direitos sociais, em seu artigo 6: "são direitos sociais a educação, a saúde, a alimentação, o trabalho, a moradia, o transporte, o lazer, a segurança, a previdência social, a proteção à maternidade e à infância, a assistência aos desamparados, na forma desta Constituição." Determinou, ainda, as diretrizes do direito à saúde no artigo 196, da CF/88, ao afirmar que "a saúde é direito de todos e dever do Estado, garantido mediante políticas sociais e econômicas que visem à redução do risco de doença e de outros agravos e ao acesso universal e igualitário às ações e serviços para sua promoção, proteção e recuperação". ${ }^{10}$

A partir da determinação Constitucional, surgem obrigações e deveres positivos de atuação do Estado em garantir e efetivar o direito à saúde de forma ampla por meio de políticas públicas. Uma das formas de atuação dá-se com a constituição da política pública denominada Sistema Único de Saúde (SUS). Com isso, a Lei Orgânica

\footnotetext{
desigual desenvolvimento em diferentes países no que respeita à promoção de saúde e combate às doenças, especialmente contagiosas, constitui um perigo comum; 6. O desenvolvimento saudável da criança é de importância basilar; a aptidão para viver harmoniosamente num meio variável é essencial a tal desenvolvimento; 7. A extensão a todos os povos dos benefícios dos conhecimentos médicos, psicológicos e afins é essencial para atingir o mais elevado grau de saúde; 8 . Uma opinião pública esclarecida e uma cooperação ativa da parte do público são de uma importância capital para o melhoramento da saúde dos povos; 9. Os Governos têm responsabilidade pela saúde dos seus povos, a qual só pode ser assumida pelo estabelecimento de medidas sanitárias e sociais adequadas; 10 . Aceitando estes princípios com o fim de cooperar entre si e com os outros para promover e proteger a saúde de todos os povos, as partes contratantes concordam com a presente Constituição e estabelecem a Organização Mundial da Saúde como um organismo especializado, nos termos do artigo 57 da Carta das Nações Unidas. (OMS, 1946).

7 WHO, World Health Organization (2008): The Right to Health. Disponível em: https://www.ohchr.org/Documents/Publications/Factsheet31.pdf, acesso em: 28.08.2019.

8 ANTUNES, Eduardo Muylaert (2016): “Natureza Jurídica da Declaração Universal dos Direitos Humanos”, en Revista dos Tribunais - Doutrinas Essenciais de Direitos Humanos, Nro. 06, Out/2016, p. 607.

9 MARKS, S. P (2013): “The emergence and scope of the human right to health”, In: ZUNIGA, J. M.; MARKS, S. P.; GOSTIN, L. O. Advancing the Human Right to Health. 1. ed. United Kingdom: OXFORD University Press, Cap. 1, p. 3-24. ISBN: 978-0-19-966161-9, p, 04.

10 BRASIL. Constituição (1988). Constituição da República Federativa do Brasil. Brasília, DF: Senado Federal, 1988.
} 
de Saúde $n^{\circ}$. 8.080/1990, em conjunto com a Lei $n^{\circ}$. 8.142/1990, estabelecem as diretrizes infraconstitucionais do direito à saúde, determinando as ações à promoção, à manutenção e recuperação da saúde que serão prestadas pelo SUS, que deve respeitar as características da universalidade, igualdade e integralidade em todos os níveis de assistência por meio de políticas públicas. Ressalta-se que a Lei $n^{\circ}$. 8.080/1990, em seu artigo $6^{\circ}$, inciso I, alínea 'd', dispõe a questão da assistência terapêutica integral, inclusive farmacêutica pelo SUS. ${ }^{11}$

O direito à saúde pode desdobrar-se em outros direitos, ou seja, é formado por um sistema complexo com aspectos fundamentais que abarcam outros direitos como:

"The right to a system of health protection providing equality of opportunity for everyone to enjoy the highest attainable level of health; The right to prevention, treatment and control of diseases; Access to essential medicines; Maternal, child and reproductive health; Equal and timely access to basic health services; The provision of health-related education and information; Participation of the population in healthrelated decisionmaking at the national and community levels." ${ }^{12} ;{ }^{13}$

A questão do direito ao acesso à medicamentos e o consequente dever de fornecimento de medicamentos pelo SUS está diretamente ligado a efetivação do direito à saúde por meio de políticas públicas adequadas, mas nem sempre é assim, conforme as autoras Martini e Sturza, verifica-se que,

"não é difícil identificar que, nesta sociedade, todos temos muito mais direitos do que podemos efetivamente gozar. A era da inclusão universal já existe, mas sua existência está fundada em situações paradoxais nas quais, muitas vezes, a inclusão se dá pela exclusão; a possibilidade de acesso ao direito de ter direito à saúde se dá, muitas vezes, não através do sistema de saúde, mas pelo sistema judiciário, ou, ainda pior, por favores políticos ou de amizade". ${ }^{14}$

A assistência farmacêutica do SUS no Brasil completou 30 anos de atividade e, durante esse período, sofreu diversas mudanças e atualizações com intuito de aperfeiçoar tal política pública. ${ }^{15}$ Contudo, "uma política pública só se concretiza quando 'o que fazer' está em sintonia com o 'como fazer"'16 e muitas das prestações estatais relacionadas ao fornecimento de medicamentos não se mostram efetivas, havendo a necessidade de

\footnotetext{
11 BRASIL. Lei n 8.080, de 19 de setembro de 1990. Dispõe sobre as condições para a promoção, proteção e recuperação da saúde, a organização e o funcionamento dos serviços correspondentes e dá outras providências. (Lei Orgânica da Saúde). Diário Oficial da República Federativa do Brasil, Brasília, DF, 20 set. 1990 .

12 Tradução Livre: O direito a um sistema de proteção da saúde proporcionando igualdade de oportunidade para que todos possam desfrutar da mais alto nível de saúde; $\mathrm{O}$ direito à prevenção, tratamento e controle de doenças; Acesso a medicamentos essenciais; Saúde materna, infantil e reprodutiva; acesso igual e oportuno aos serviços básicos de saúde; $\mathrm{O}$ fornecimento de educação e informação relacionada com a saúde; Participação da população em decisões relacionadas à saúde fazendo nos níveis nacional e comunitário.

13 WHO, World Health Organization (2008): Op. Cit.

14 MARTINI, Sandra Regina; STURZA, Janaína Machado (2019): Op. Cit., p. 20.

15 BERMUDEZ, Jorge Antonio Zepeda et al (2018): "Assistência Farmacêutica nos 30 anos do SUS na perspectiva da integralidade”, Ciência \& Saúde Coletiva, V. 23, Nro. 6, [s.l.], p.1937-1949, jun.

16 BARROS, Maria Elizabeth Barros de; GUEDES, Carla Ribeiro; ROZA, Monica Maria Raphael (2011): "O apoio institucional como método de análiseintervenção no âmbito das políticas públicas de saúde: a experiência em um hospital geral”, Ciência \& Saúde Coletiva, V. 16, Nro. 12, Rio de Janeiro, p. 4803-4814, dez. 2011, p. 4804).
} 
judicialização.

\section{Judicialização de Políticas Públicas em Saúde}

A interferência em políticas públicas pelo Poder Judiciário é realidade já estabelecida no Brasil há muitos anos. Isso pode ocorrer em processos coletivos ou individuais. Quando o faz em processos individuais, no entanto, repetidamente o faz com total irresponsabilidade, como registra Sérgio Arenhart: "irresponsabilidade não porque os juízes que atuam nesses processos ajam de modo incorreto, mas porque os instrumentos processuais empregados para esse controle são manifestamente inadequados."17

Pode-se afirmar que, em alguns casos, há interferência indevida nas políticas públicas, mormente na área da saúde, pois os magistrados não detêm o conhecimento técnico necessário de alta complexidade que envolve essas questões. Nem se imagina que devessem tê-lo, a priori, em todas as demandas. Mas é justamente a partir do estabelecimento do fato de que o julgador especializa-se em Direito (não em Medicina, Engenharia, Psicologia, dentre outros), que ele deve se cercar de experts que o abasteçam das informações necessárias.

Há de considerar também que "nunca tivemos tantos direitos assegurados a partir de Constituições, pactos e acordos e, ao mesmo tempo, observações quanto à não efetivação destes direitos constitucionalizados ou pactuados. Ao ampliarem-se os direitos, os mesmos perdem força. ${ }^{18}$ Isso faz com que se apresente a necessidade de maior intervenção judicial. E, diante dessa realidade, "o crescimento das demandas judiciais na área da saúde, assim como as demandas em saúde no interior do próprio sistema de saúde fazem ver a fragilidade das nossas políticas públicas, que não deram conta de efetivar este direito, recentemente constitucionalizado na América Latina."19

O Conselho Nacional de Justiça apresentou relatório em março de 2019 a respeito da judicialização da saúde no Brasil. Conforme o estudo, "o número de demandas judiciais relativas à saúde aumentou 130\% entre 2008 e 2017, enquanto o número total de processos judiciais cresceu 50\%."20 O Ministério da Saúde registrou, nesse mesmo período, um aumento de 13 vezes em suas despesas com demandas judiciais, atingindo $\mathrm{R} \$ 1,6$ bilhão em 2016. Os dados revelam que a questão se agravou nesse período, demonstrando a lentidão do Poder Executivo em implementar uma parte da política pública em matéria de saúde. Uma das relevantes propostas do estudo é de que os cursos de formação de magistrados devem abordar as temáticas relativas ao direito sanitário, dado que sua incorporação nas cartas constitucionais é fenômeno recente. ${ }^{21}$

De outro lado, ainda que de forma lenta, o Poder Legislativo também se movimenta para auxiliar o Poder Judiciário na implementação dessas políticas, o que reconhece a importância de participação deste Poder nessa tarefa. O Projeto de Lei 8.058/2014 tem como objetivo preencher lacunas em matéria processual na instituição de

\footnotetext{
17 ARENHART, Sergio Cruz (2015): "Processos estruturais no direito brasileiro: reflexões a partir do caso da ACP do carvão", en Revista de Processo Comparado, V. 1, Nro. 2, RPC, pp. 211-229, jul./dez, pp. 212.

18 MARTINI, Sandra Regina; STURZA, Janaína Machado (2019): Op. Cit., p. 44.

19 MARTINI, Sandra Regina; STURZA, Janaína Machado (2019): Op. Cit., p. 45.

20 CONSELHO NACIONAL DE JUSTIÇA. Judicialização Da Saúde No Brasil: Perfil Das Demandas, Causas e Propostas De Solução. Disponível em: http:// www.cnj.jus.br/files/ conteudo/arquivo/2019/03/66361404dd5ceaf8c5f7049223bdc709.pdf, acesso em: 29.08.2019.

21 CONSELHO NACIONAL DE JUSTIÇA. Judicialização Da Saúde No Brasil: Perfil Das Demandas, Causas e Propostas De Solução. Disponível em: http:// www.cnj.jus.br/files/ conteudo/arquivo/2019/03/66361404dd5ceaf8c5f7049223bdc709.pdf, acesso em: 29.08.2019, pp. 144.
} 
políticas públicas, sejam elas relacionadas à tutela coletiva ou individual, pois contém o reconhecimento de que existem políticas públicas sendo realizadas em demandas individuais, a partir do que dispõe o art. 28 do PL.

A redação do parágrafo único do artigo 28 do PL é muito adequada, pois determina que “cada circunscrição judiciária organizará e manterá comissão de especialistas destinada a assessorar o magistrado nos diversos setores de políticas públicas, fornecendo dados e informações que o auxiliem em sua decisão." À toda evidência, não se trata de Projeto que verse exclusivamente sobre questões na área da saúde, mas em todas as demandas que envolvam políticas públicas. Impõe-se examinar, ainda, como o Judiciário vem implementando as políticas públicas em matéria de medicamentos.

\section{O Fornecimento Judicial e Medicamentos}

O acesso ao Judiciário, em qualquer demanda, deve ser mediado pelo modelo mínimo de garantias apresentado pelo processo justo. ${ }^{22}$ Esses direitos oriundos do direito fundamental ao processo justo derivam do catálogo aberto de direitos fundamentais da Carta Constitucional brasileira e até mesmo dos Pactos Internacionais em Direitos Humanos. ${ }^{23}$ Para o presente estudo, impõe que se considere que o direito fundamental à tutela adequada e efetiva merece atenção. Deve ser lembrado seu tríplice aspecto, tanto no viés de acesso à justiça, como de adequação da tutela e de efetividade da tutela. ${ }^{24}$

Não se pode descurar, no entanto, de que as demandas envolvendo medicamentos nunca são singulares. Para cada demanda solicitando medicamentos, existem diversas outras, espalhadas pelo país, requerendo o mesmo tipo de fármaco para o mesmo tipo de condição. O que leva a considerar a relevância do direito à igualdade, pois não se pode imaginar que, para uma mesma situação, um desses jurisdicionados obtenha o fármaco e o outro não. A fina malha da segurança jurídica, tecida a partir da igualdade processual, não apenas no, mas também pelo processo, há de ser considerada. ${ }^{25}$ Por isso os critérios apresentados pelo Superior Tribunal de Justiça merecem estudo, bem como o uso da ferramenta e-Natjus.

\section{Requisitos Para a Concessão de Medicamentos}

O Superior Tribunal de Justiça (STJ), no julgamento do RESP 1657156/RJ, tratou dos requisitos para concessão de medicamentos que se encontram fora da lista fornecida pelo Sistema Único de Saúde (SUS). A matéria foi julgada no Rito de Recurso Repetitivo com intuito de criar parâmetros que balizem a ação do judiciário nesse tipo de demandas.

No julgamento, que ocorreu em 25 de abril de 2018, a tese firmada pelos Ministros do STJ foi no sentido de que o Estado está obrigado a fornecer medicamentos ainda que estes não façam parte da lista do SUS, porém, para que isso ocorra se faz necessário que critérios sejam estabelecidos. O STJ entendeu que três critérios devem ser atendidos, de maneira cumulativa, quais sejam: a) o demandante tem que comprovar a sua hipossuficiência para adquirir o medicamento pleiteado; b) o medicamento demandado deve estar registrado na Agência Nacional de Vigilância Sanitária (ANVISA); c) o laudo médico que prescreveu o referido medicamento deverá estar devidamente fundamentado, deverá

\footnotetext{
22 SARLET, Ingo Wolfgang, MARINONI, Luiz Guilherme, MITIDIERO, Daniel (2012): Curso de Direito Constitucional, RT, São Paulo, pp. 616. 23 Como se vê, por exemplo, nos artigos $8^{\circ}$ e 25 do Pacto de São José da Costa Rica.

24 SARLET, Ingo Wolfgang, MARINONI, Luiz Guilherme, MITIDIERO, Daniel (2012): Op. Cit., p. 628.

25 ABREU, Rafael Sirangelo de (2015): Igualdade e Processo, RT, São Paulo.
} 
explicar a necessidade do medicamento específico e o porquê os medicamentos que são fornecidos pela rede pública não se enquadram ao tratamento do demandante.

A partir dos critérios apresentados passaremos a analisar os requisitos impostos pelo STJ para a concessão dos medicamentos fora do padrão fornecido pelo SUS. Pois, como já referido, a entrega de medicamentos pela rede pública está ligada a efetivação do Direito à saúde. Por essa linha, a pergunta que se deve fazer é no sentido de que se há uma limitação dos critérios para fornecimento de medicamentos, não se estaria, ao mesmo, tempo limitando o acesso à saúde? Para responder a esse questionamento é fundamental a análise dos três requisitos impostos pelo STJ.

O primeiro critério exige a comprovação, por meio de laudo fundamentado, da necessidade do medicamento pleiteado, bem como da ausência de eficácia no tratamento da doença pelos fármacos disponíveis no SUS. Este critério trata de um ponto importante que é a necessidade do médico, que geralmente atende na rede pública, justificar o motivo pelo qual prescreveu um medicamento que sabe não ser fornecido pelo SUS. Esse critério não foi uma inovação do Tribunal, pois já existia esse entendimento ${ }^{26}$ de que os aspectos que tratam da eficiência e eficácia do tratamento devem ser fundamentados pelo profissional competente que os receitou.

O segundo refere a incapacidade financeira da parte para arcar com o tratamento. Diferentemente da esfera administrativa, em que a renda não é por si só um critério para que se negue o acesso ao direito à saúde, quando se entre no âmbito judicial, a renda deve ser um fator relevante, pois tratamos de um tema que é extremamente judicializado e um campo do Estado que tem recursos limitados.

É importante lembrar, nesse ponto, que a hipossuficiência não é sinônimo de pobreza. O critério é que a pessoa comprove, que com a renda que possui não tem condições de arcar com os custos do tratamento de que necessita sem que haja o comprometimento de sua renda. Conforme o Ministro Benedito Gonçalves, "não se exige, pois, comprovação de pobreza ou miserabilidade, mas, tão somente, a demonstração da incapacidade de arcar com os custos referentes à aquisição do medicamento prescrito."27

No que tange ao terceiro requisito, exige-se a existência de registro junto à ANVISA do referido medicamento pode-se dizer que o fato de um medicamento possuir um registro junto ao órgão regulador traz ao julgador uma garantia de que aquele fármaco passou por diversos teste e critérios definidos por especialista técnicos que comprovam sua eficácia para determinado tratamento de saúde.

Outro ponto da decisão que merece destaque é o fato de que o Tribunal determinou que após o trânsito em julgado da decisão que determinou o fornecimento de um medicamento fora da lista do SUS, que sejam oficiados o Ministério da Saúde e a Comissão Nacional de tecnologias do SUS para que estes procedam um estudo sobre a viabilidade de inclusão do medicamento na lista dos fornecidos pela rede pública.

26 BRASIL. Superior Tribunal de Justiça. RESP. n 1.643.607/RR; RESP. nº 1513597/MG; REsp nº 1.660.425/RJ, disponíveis em www.stj.jus.br. Acesso em 24 de agosto de 2019.

27 BRASIL. Superior Tribunal de Justiça. REsp. n 1.660.425/RJ. Disponível em: https://stj.jusbrasil.com.br/jurisprudencia/574252474/recurso-especialresp-1657156-rj-2017-0025629-7/inteiro-teor-574252509, acesso em 29.08.2019. 
O Superior Tribunal de Justiça estabelece esse entendimento a fim de uniformizar a aplicação da lei federal, função que Ihe é própria, no que diz respeito ao fornecimento de medicamentos. Tal como já tinha realizado em matéria de ações revisionais, criando critérios que depois viriam a ser incorporados ao Código de Processo Civil, o STJ estreita as bases a partir das quais um fármaco possa ser concedido ao indivíduo sem que se recorra a fórmulas vagas obtidas em conceitos abertos.

Faz-se, portanto, necessário analisar questões de ordem técnica e regulatória, além da questão econômica do indivíduo que necessita do tratamento. Esses critérios se revelam necessários na medida em que se deve assegurar igualdade de tratamento processual àqueles que acessam o Poder Judiciário, reconhecida como uma igualdade pelo processo. Como bem saliente Rafael Abreu:

O "tratamento diverso em casos iguais, sem as devidas diferenças relevantes, significa vulnerar frontalmente a igualdade, da mesma forma com que será afrontada no caso de aplicação do precedente sem consideração das diferenças substanciais do caso. Não há como fugir da constatação de que a igualdade é o fundamento natural e dogmático dos precedentes." ${ }^{28}$

Assim, ao considerarmos os critérios definidos pelo STJ pode-se dizer que o intuito do Tribunal não é o de limitar o acesso ao direito à saúde. É, sim, de otimizar a prestação jurisdicional para que sejam fornecidos os tratamentos adequados aos demandantes sem que haja desperdício de dinheiro público, com tratamentos inadequados ou que não possuam comprovação de sua eficácia, entregando, a final, prestação jurisdicional igualitária perante os jurisdicionados.

\section{O Uso da Ferramenta e-Natjus Como Requisito?}

Um dos maiores problemas encontrados pela e na judicialização da saúde decorre da falta de conhecimento técnico dos Magistrados com relação ao tema. As demandas acabam sendo julgadas sem fundamentação técnica e objetiva dos juízes, mas sim, conforme suas motivações subjetivas e convicções morais. ${ }^{29}$

Contudo, essas decisões requerem um apoio técnico qualificado, pois seus resultados possuem reflexos amplos que envolvem, direta e indiretamente, todo o Poder Público. Nas palavras dos autores Forster e Cavalheiro,

“[...] o Poder Judiciário não possui amplo rol de experts a fim de esclarecer quais são os medicamentos efetivamente necessários e eficazes para determinada condição. O ponto delicado não é só, como em todo caso de saúde pública, o tema da limitação orçamentária, mas também a atuação de pessoas sem qualificação técnica na área da saúde determinando essa alocação de recursos para aquisição de medicamentos cujo funcionamento e eficácia desconhecem." ${ }^{130}$ 
Em vista disso, no ano de 2016, com o intuito de aperfeiçoar as atividades dos órgãos judiciais, o Conselho Nacional de Justiça (CNJ) por meio da Resolução $n^{\circ}$. 238, estabeleceu a criação de Comitês Estaduais e/ou Distritais de Saúde, de Núcleos de Apoio Técnico do Judiciário (NAT-JUS) e a criação de um Sistema Nacional de Pareceres e Notas Técnicas (e-Natjus), bem como, a especialização das Varas Judiciais competentes para julgar demandas de saúde. A partir das diretrizes formuladas, o Núcleo de Apoio Técnico do Judiciário (e-Natjus) foi lançado em novembro de 2017 e implementado em dezembro de 2018.

O Conselho Nacional de Justiça ao considerar que a judicialização da saúde envolve questões complexas, adota medidas que visam a especialização de seus Magistrados afim de que suas decisões sejam munidas de técnica e precisão. Ainda, o órgão vem adotando medidas concretas e normativas voltadas à prevenção de conflitos judiciais e definindo estratégias de prevenção e resolução de questões que envolvam direito sanitário. ${ }^{31}$

Nesse sentido, no mês de agosto de 2019, o CNJ editou o Provimento n. 84, que dispõe sobre o uso e o funcionamento do sistema e-Natjus. Basicamente, o sistema funciona como uma plataforma nacional de cadastro de pareceres, notas e informações técnicas da área da saúde. Tem como objetivo principal auxiliar os magistrados em suas decisões judiciais (liminares), uma vez que, fornecem fundamentos científicos para que decidam com segurança nas suas demandas que tenham como objeto pedido de medicamentos, órtese, prótese ou qualquer outra tecnologia em saúde. ${ }^{32}$

Importante frisar que as decisões dos magistrados, em matéria de direito sanitário, não estão vinculadas ao uso da ferramenta e-Natjus, na linha do que dispõe o art. $1^{\circ}$ do Provimento 84/2019 do CNJ.33 O provimento traz o apoio técnico como sendo uma possibilidade aos juízes, não impondo um dever de solicitar apoio técnico ao NAT-JUS.

Contudo, uma vez solicitado o apoio técnico, ele "deverá ser materializado por meio do Sistema Nacional de Pareceres e Notas Técnicas (e-Natjus), hospedado no sítio do Conselho Nacional de Justiça [...]". ${ }^{34}$ No caso de um Tribunal possuir um sistema próprio de apoio técnico e este apoio emitir parecer a um caso concreto, o NATJUS tem o dever de alimentar a base de dados do e-Natjus com o material produzido.

O sistema pode ser consultado de forma aberta pelo público, trazendo informações que são relevantes não apenas aos julgadores, mas também aos solicitantes de medicamentos via judicial. Uma rápida consulta fornece informações sobre o medicamento, contextualiza a doença para o qual é mais indicado, fornece evidências científicas de sua eficácia e justificativa para sua possível recomendação, concluindo, a partir de sólida base científica, pela força de recomendação do medicamento.

Com relação a relevância da parceria entre o apoio técnico médico-científico e o CNJ

\footnotetext{
31 CONSELHO NACIONAL DE JUSTIÇA (2019): Provimento n 84, de 14 de agosto de 2019. Disponível em: http://www.cnj.jus.br/images/atos_ normativos/provimento/provimento_84_14082019_22082019175759.pdf, acesso em: 29.08.2019.

32 CONSELHO NACIONAL DE JUSTIÇA (2019): Op. Cit.

33 Art. $1^{\circ}$ Os Magistrados Estaduais e os Magistrados Federais com competência para processar e julgar ações que tenham por objeto o direito à saúde, ainda que durante o plantão judicial, quando levados a decidirem sobre a concessão de determinado medicamento, procedimento ou produto, poderão solicitar apoio técnico ao Núcleo de Apoio Técnico do Judiciário (NAT-JUS) do seu Estado ou ao NAT-JUS NACIONAL.

34 CONSELHO NACIONAL DE JUSTIÇA (2019): Op. Cit.
} 
e, sua iniciativa para a implementação do sistema eletrônico e-Natjus - nas demandas judiciais envolvendo o indispensável direito à saúde - traz-se as autoras Martini e Sturza ensinando que o direito deve prezar pela multidisciplinariedade de conhecimentos para acompanhar os novos fenômenos sociojurídicos. Pois, justamente, "em conjunto com as mais diversas áreas do conhecimento, que o direito moderno deve ser estudado, aplicado e refletido, e não apenas como tradicionalmente vem ocorrendo, a partir da ótica dogmática e formalista. Estudar o direito a partir de uma visão fraterna, importa em construir um novo referencial para a própria ciência do direito, o qual deve se fundamentar em outras áreas de estudos que estão intrinsecamente ligadas "com" e "nos" fenômenos sociojurídicos." ${ }^{35}$

Assim, demonstra-se a importância e utilidade do sistema e-Natjus ao Poder Judiciário e por consequência, ao Poder Executivo. A ferramenta, se bem utilizada, proporciona maior segurança jurídica e igualdade às decisões judiciais em âmbito nacional, bem como às partes do processo judicial em matéria de direito à saúde, que buscam efetivar seu direito humano fundamental judicialmente, uma vez que as políticas públicas não suprimiram suas necessidades básicas/essenciais.

\section{Considerações Finais}

Todo processo judicial deve assegurar um modelo mínimo de garantias a fim de que o jurisdicionado possa obter uma decisão justa. A justiça da decisão em matéria de fornecimento de medicamentos é de alta complexidade, especialmente quando pensada não apenas a partir da efetividade da tutela pretendida, mas também sob a ótica do contraditório, da segurança jurídica e da igualdade processual. Os critérios propostos pelo Superior Tribunal de Justiça auxiliam na realização de políticas públicas na área da saúde pelo Poder Judiciário, trazendo maior estabilidade ao tema. Agora, com a ferramenta e-Natjus, estruturada pelo Conselho Nacional de Justiça, os magistrados tem uma relevante ferramenta técnica para o incremento da qualidade do provimento jurisdicional, que não se baseará apenas em elementos trazidos pela parte autora.

Diga-se que o próprio autor também pode se beneficiar da consulta à plataforma em sua porção aberta, pois há diversos pareceres e notas técnicas que esclarecem a eficácia dos medicamentos e a chance de obtê-los judicialmente. A ferramenta, portanto, não apresenta um requisito adicional para a concessão de medicamentos via Judiciário. A importância de seu uso, contudo, quase a eleva a esse patamar, a fim de que os provimentos jurisdicionais não se baseiem em fórmulas jurídicas vagas para a concessão de medicamentos que podem ter resultados menos do que benéficos ao próprio requerente. 


\section{REFERÊNCIAS BIBLIOGRÁFICAS}

- ABREU, Rafael Sirangelo de (2015): Igualdade e Processo, RT, São Paulo.

- ANTUNES, Eduardo Muylaert (2016): “Natureza Jurídica da Declaração Universal dos Direitos Humanos", en Revista dos Tribunais - Doutrinas Essenciais de Direitos Humanos, Nro. 06, Out/2016, p. 607.

- ARENHART, Sergio Cruz (2015): "Processos estruturais no direito brasileiro: reflexões a partir do caso da ACP do carvão", en Revista de Processo Comparado, V. 1, Nro. 2, RPC, pp. 211-229, jul./dez.

- BARROS, Maria Elizabeth Barros de; GUEDES, Carla Ribeiro; ROZA, Monica Maria Raphael (2011): “O apoio institucional como método de análise-intervenção no âmbito das políticas públicas de saúde: a experiência em um hospital geral", Ciência \& Saúde Coletiva, V. 16, Nro. 12, Rio de Janeiro, p. 4803-4814, dez. 2011.

- BERMUDEZ, Jorge Antonio Zepeda et al (2018): "Assistência Farmacêutica nos 30 anos do SUS na perspectiva da integralidade", Ciência \& Saúde Coletiva, V. 23, Nro. 6, [s.l.], p.1937-1949, jun.

- BRASIL. Constituição (1988). Constituição da República Federativa do Brasil. Brasília, DF: Senado Federal, 1988.

- BRASIL. Superior Tribunal de Justiça. REsp no 1.657.156/RJ. Disponível em: https:// stj.jusbrasil.com.br/jurisprudencia/574252474/recurso-especial-resp-1657156rj-2017-0025629-7/inteiro-teor-574252509, acesso em: 29.08.2019.

- BRASIL. Superior Tribunal de Justiça. REsp no 1.643.607/RR. Disponível em: https:// stj.jusbrasil.com.br/jurisprudencia/450060966/recurso-especial-resp-1643607rr-2016-0322878-7/decisao-monocratica-450060979, acesso em 29.08.2019

- BRASIL. Superior Tribunal de Justiça. REsp n 1.513.597/MG. Disponível em: https:// stj.jusbrasil.com.br/jurisprudencia/629279671/recurso-especial-resp-1513597mg-2015-0030424-4, acesso em 29.08.2019.

- BRASIL. Superior Tribunal de Justiça. REsp. n 1.660.425/RJ. Disponível em: https:// stj.jusbrasil.com.br/jurisprudencia/574252474/recurso-especial-resp-1657156rj-2017-0025629-7/inteiro-teor-574252509, acesso em 29.08.2019.

- BRASIL. Lei $n^{\circ}$ 8.080, de 19 de setembro de 1990. Dispõe sobre as condições para a promoção, proteção e recuperação da saúde, a organização e o funcionamento dos serviços correspondentes e dá outras providências. (Lei Orgânica da Saúde). Diário Oficial da República Federativa do Brasil, Brasília, DF, 20 set. 1990.

- CONSElHO NACIONAL DE JUSTIÇA. Judicialização Da Saúde No Brasil: Perfil Das Demandas, Causas e Propostas De Solução. Disponível em: http://www.cnj.jus.br/files/ conteudo/arquivo/2019/03/66361404dd5ceaf8c5f7049223bdc709.pdf, acesso em: 29.08.2019.

- CONSELHO NACIONAL DE JUSTIÇA (2019): Provimento $n^{\circ}$ 84, de 14 de agosto de 2019. Disponível em: http://www.cnj.jus.br/images/atos_normativos/provimento/ provimento_84_14082019_22082019175759.pdf, acesso em: 29.08.2019.

- FORSTER, João Paulo K.; CAVALHEIRO, Andressa Fracaro (2013): “Limitações éticas à prescrição de medicamentos: dos impactos no protocolo SUS ao posicionamento do Poder Judiciário", Cadernos Ibero-americanos de Direito Sanitário, V. 2, Nro. 2, [s.l.], p.365-380, 20 dez.

- WHO, World Health Organization (2008): The Right to Health. Disponível em: https:// www.ohchr.org/Documents/Publications/Factsheet31.pdf, acesso em: 28.08.2019.

- MARKS, S. P (2013): "The emergence and scope of the human right to health", In: ZUNIGA, J. M.; MARKS, S. P.; GOSTIN, L. O. Advancing the Human Right to Health. 1. ed. United Kingdom: OXFORD University Press, Cap. 1, p. 3-24. ISBN: 978-0-19-966161-9. 
- MARTINI, Sandra Regina; STURZA, Janaína Machado (2019): Direitos Humanos: saúde e fraternidade, Evangraf, Porto Alegre.

- OMS, Organização Mundial da Saúde. Constituição da Organização Mundial da Saúde (OMS/WHO) - 1946. Disponível em: http://www.direitoshumanos.usp.br/index.php/OMSOrganiza\%C3\%A7\%C3\%A3o-Mundial-da-Sa\%C3\%BAde/constituicao-da-organizacaomundial-da-saude-omswho.html, acesso em: 28.08.2019.

- SARLET, Ingo Wolfgang, MARINONI, Luiz Guilherme, MITIDIERO, Daniel (2012): Curso de Direito Constitucional, RT, São Paulo.

- ZEBULUM, J. C (2018): “Os conflitos morais enfrentados pelos juízes em demandas de saúde: o caso dos tribunais federais brasileiros", en Revista de Direito Sanitário, V. 19, Nro. 1, p. 144-165, 13 jul. 